\title{
Efficiency removal of phenol, lead and cadmium by means of $\mathrm{UV} / \mathrm{TiO}_{2} / \mathrm{H}_{2} \mathrm{O}_{2}$ processes
}

\author{
M. R. Samarghandi, ${ }^{*} J$. Nouri, A. R. Mesdaghinia, A. H. Mahvi, S. Nasseri, F. Vaezi \\ Department of Environmental Health Engineering, School of Public Health and Institute of Health Researches, \\ Tehran University of Medical Sciences, Tehran, Iran
}

Received 28 November 2006; revised 18 December 2006; accepted 25 December 2006; available online 1 January 2007

\begin{abstract}
A variety of processes can be used in treatment of industrial wastewaters. The relatively newest of which is photo catalysis with titanium dioxide which may also be used plus hydrogen peroxide to improve the treatment rate. In this study, photo catalysis/ hydrogen peroxide processes had been employed for the removal of phenol, lead and cadmium by three different pHs of 3.5, 7 and 11. The treatment tests were also accomplished without UV irradiation. In both experiments, the variables were $\mathrm{pH}$ and concentrations of reagent chemicals, but the detention time was kept constant (180 min). Results indicated that the optimum efficiencies of phenol and Cd removal were 76 $\%$ and $97.7 \%$ at $\mathrm{pH}=11$, respectively, and for lead, it was $98.8 \%$ in all $\mathrm{pHs}$. In other words, no $\mathrm{pH}$ dependency was regarded for lead treatment. These results were all obtained by simultaneous use of UV irradiation with $3 \mathrm{~mL} / \mathrm{L} \mathrm{H}_{2} \mathrm{O}_{2}$ and $0.8 \mathrm{~g} / \mathrm{L} \mathrm{TiO}_{2}$. Finally, the best $\mathrm{pH}$ for treatment, when all the three contaminants are presented is considered to be at 11 . These results should be regarded by all industrial treatment plants which have experienced the problem of these three special contaminants in their effluents.
\end{abstract}

Key words: Phenol, heavy metals, titanium dioxide, hydrogen peroxide process, photo catalysis

\section{INTRODUCTION}

In regard with hazardous effects of organic and mineral pollutants, today various methods are used for their removal from Industrial wastewater. One of the relatively new methods for this purpose is photocatalysis process by $\mathrm{TiO}_{2}$ (Desrosiers, et al., 2006). Titanium dioxide has a good capacity to degredate organic compounds(Akbal, et al., 2003) by oxidation and also remove heavy metals by reduction of them.(Prairie, et al., 1998). It is relatively inexpensive, insoluble in water and nonpoisonous. (Vidol, et al., 1999). The process of photocatalysis is relatively simple. Light energy from ultraviolet radiation in the form of photons, below $390 \mathrm{~nm}$, excites the electrons on the surface of titanium atoms suspended in the contaminated water (Poudyal, et al., 2006). On the other hand, when $\mathrm{TiO}_{2}$ is illuminated with the light of $\lambda<390$ $\mathrm{nm}$, electrons are promoted from the valence band to the conduction band of the semi-conducting oxide to give election- hole pairs. The valence band $\left(\mathrm{h}_{\mathrm{VB}}^{+}\right)$ potential is positive enough to generate hydroxyl radicals at the surface and the conduction band $\left(\mathrm{e}_{\mathrm{CB}}^{-}\right)$

*Corresponding author, Email: jnouri@tums.ac.ir

Tel/Fax: +9821 88989133 potential is negative enough to reduce molecular oxygen. (Daneshvar, et al.,2004) The hydroxyl radical is a powerful oxidizing agent and attacks organic pollutants present at or near the surface of $\mathrm{TiO}_{2}$. It causes photo oxidation of pollutants (Bekkouche, et al., 2004). By contrast, photo catalytic reduction takes place when hole scavenger is adapted, and the photo generated electrons are allowed to undergo cathode reaction. A potential and very attractive practical application of light- driven photo catalytic reduction is the deposition of harmful toxic metal, and recovery of noble metals from industrial waste effluents. The metals are deposited onto The surface of semiconductor catalyst powders, and can subsequently be extracted from the slurry by mechanical and/ or chemical means (Chen, et al., 2001). Therefore, the following redox reaction cycle (photo catalytic oxidation and reduction) takes place:

$$
\begin{aligned}
& \mathrm{TiO}_{2}+h v(\lambda \leq 380 n m) \rightarrow \mathrm{TiO}_{2}\left(e^{-}+h^{+}\right) \\
& \mathrm{M}^{n+}+e^{-} \rightarrow \mathrm{M}^{(n-1)+}, \\
& \mathrm{OH}^{-}+h^{+} \rightarrow \mathrm{OH}^{0},
\end{aligned}
$$


$\mathrm{OH}^{0}+\mathrm{RH} \rightarrow \mathrm{R}^{0}+\mathrm{H}_{2} \mathrm{O} \rightarrow \mathrm{CO}_{2}+\mathrm{H}_{2} \mathrm{O}+$ Mineral acids, $2 \mathrm{H}_{2} \mathrm{O}+4 h^{+} \rightarrow \mathrm{O}_{2}+4 \mathrm{H}^{+}$

Where $\mathrm{M}$ represents the metal ion and $\mathrm{RH}$ organic compounds. In 2001, Vohra (Vohra, et al., 2002) reported of his research about photo catalytic degradation of nitro toluene in aqueous $\mathrm{TiO}_{2}$ suspension. This process was employed to treat aqueous 2,3 and 4 nitro toluene pollutants. Another study was carried out by coinstantaneous (Konstantinou, et al., 2002). In this study ,the light-induced degradation of propachlor (2chloro-Nisopropylacetanilide) under simulated solar irradiation has been investigated in aqueous solutions containing $\mathrm{TiO}_{2}$ suspensions as photo catalysts. The study focuses on the identification of possible intermediate products and on the determination of inorganic ions formed during the process. Although many researches have been performed about use of photo catalysis processes in treatment of industrial wastewaters, this study should be regarded novel, because the efficiency of $\mathrm{UV} / \mathrm{TiO}_{2} / \mathrm{H}_{2} \mathrm{O}_{2}$ process has been determined for the first time in simultaneous removal of Phenol "as an organic pollutant "and heavy metals "Pb and Cd as two inorganic pollutants "under different conditions of treatment.

\section{MATERIALS AND METHODS}

Instruments for analysis

Atomic absorption spectrophotometer, Thermo Jarrell Ash model SH22 for heavy metals analyses. 2.
UV/VIS spectrophotometer model Shimatzu 1700 For Phenol measurement 3. Magnetic stirrer model Hanna, 4. Ultraviolet lamp (medium pressure) $300 \mathrm{~W}$, French ARDA model 5. Digital Balance model Sartorias 6. pH meter model CG824 Schott.

\section{Chemicals}

The reagents and synthetic solutions used in this study were all prepared by use of analytical grade chemicals, which were supplied from MERK Co. as follows: Phenol, Lead nitrate, Cadmium nitrate, Sodium hydroxide, Hydrogen peroxide $35 \%$ W/V, Nitric Acid, Sulfuric acid, Potassium dehydrogenate phosphate, Potassium hexa cyan ferric and 4-amino, 2,3 dimethyl, 1 phenyl, 3-pyrazolin. Other chemicals used were titanium dioxide, Degauss mark, Particles with average diameter of 30 nanometer having $50 \mathrm{~m}^{2}$ area/g and potassium hydrogen phosphate which was supplied from Aldrich Co.

\section{Batch reactor description}

The treatment system consisted of rectangular glass reactor of $20 \times 20 \times 17 \mathrm{Cm}$ dimensions, and a larger chamber as cooling bath (Fig. 1) for circulating cold water around the reactor. A 300 watts low pressure UV lamp inside a quartz jacket was submerged in the reactor to provide better irradiation of water samples. This reactor had been operated continuously, and stirred by use of a simple magnetic stirrer.

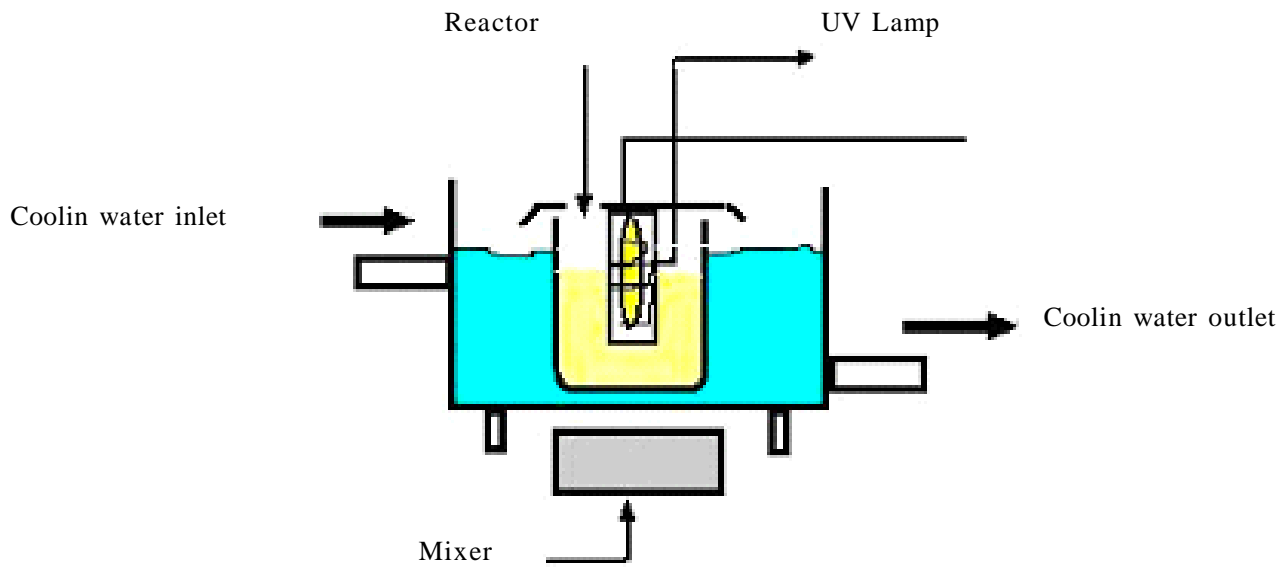

Fig. 1: Designed reactor in experimental stages 
Int. J. Environ. Sci. Tech., 4 (1): 19-25, 2007

Table 1: $\mathrm{H}_{2} \mathrm{O}_{2}$ and $\mathrm{TiO}_{2}$ concentration without UV lamp application

\begin{tabular}{lllll}
\hline $\mathrm{H}_{2} \mathrm{O}_{2(\mathrm{ml} / \mathrm{L})}$ & 3 & 2 & 1.1 & 0 \\
\hline $\mathrm{TiO}_{2(\mathrm{~g} / \mathrm{L})}$ & 0.8 & 0.3 & 0.1 & 0 \\
\hline
\end{tabular}

\section{Samples}

For making samples with concentration ranges similar to industrial effluents, three stock solutions of Phenol, Lead and Cd were first prepared according to directions outlined in Standard Method (Clesceri, et al., 2000). Then the desired solutions were made by successive dilution of the stock solutions by de ionized water. Concentrations used for this study were $500 \mathrm{mg}$ Phenol per liter and $10 \mathrm{mg} / \mathrm{L}$ for each of the metal ions.

\section{Treatment}

For bench- scale experiments, synthetic samples of Phenol, Lead and Cadmium had been used instead of industrial effluent samples. All these experiments had been accomplished in reactor with a capacity of 5 liters, and variables studied include $\mathrm{pH}, \mathrm{TiO}_{2}$ and $\mathrm{H}_{2} \mathrm{O}_{2}$ concentrations. The main two stages of tests were as follows:

Without use of UV lamp: In the first phase, this study tested four different concentrations of chemicals $\left(\mathrm{H}_{2} \mathrm{O}_{2}\right.$ and $\mathrm{TiO}_{2}$ ) at three different pHs (3.5, 7 and 11) for treatment (Table 1). The detention time of these experiments was 180 minutes. To determine the efficiency of treatment, enough samples were regularly taken before and after chemicals addition and then were analyzed for heavy metals and Phenol measurements. By use of UV lamp, the above - mentioned tests were also accomplished by use of UV irradiation. For this phase of the study, $\mathrm{TiO}_{2}$ and $\mathrm{H}_{2} \mathrm{O}_{2}$ concentrations used were somehow different. As shown in Table 2, six concentrations of chemicals at the three same pHs of 3.5, 7 and 11 had been selected for these treatment tests.

\section{RESULTS}

Results can be classified as follows:

At the first, effect of $\mathrm{pH}$ changes is evaluated. Results of this part of our study can be regarded as treatment levels which are obtainable merely by changes of $\mathrm{pH}$ (namely without use of $\mathrm{H}_{2} \mathrm{O}_{2}$ and $\mathrm{TiO}_{2}$ ). These results are presented in Table 3 under the title of stage 1 of the experiments. Secondly, effect of treatment by $\mathrm{H}_{2} \mathrm{O}_{2}$ and $\mathrm{TiO}_{2}$ are evaluated .Without UV lamp application for this part of the study which was accomplished without UV irradiation, three concentrations of $\mathrm{H}_{2} \mathrm{O}_{2}(1.1,2$ and 3) had been used. In each of combinations, the
Table 2: $\mathrm{H}_{2} \mathrm{O}_{2}$ and $\mathrm{TiO}_{2}$ concentration with UV lamp application

\begin{tabular}{llllll}
\hline $\mathrm{H}_{2} \mathrm{O}_{2(\mathrm{~m} / \mathrm{L})}$ & 2 & 1.1 & 0 & 0 & 0 \\
\hline $\mathrm{TiO}_{2(\mathrm{~g} / \mathrm{L})}$ & 0.3 & 0.1 & 0.8 & 0.1 & 0.05 \\
\hline
\end{tabular}

concentrations of Tio2 were $0.05,0.3$ and $0.8 \mathrm{~g} / \mathrm{L}$, respectively. The tests had been done at 3 mentioned pHs (Table 3, treatment stages of 2, 3 and 4). In the third steps of experiments, effects of combinations of chemicals and UV light are examined. Results of this part of our study clearly showed the synergistic effects of light on better removal of pollutants by $\mathrm{H}_{2} \mathrm{O}_{2}$ and $\mathrm{TiO}_{2}$. As mentioned, these tests had been accomplished by use of six different concentrations of chemicals and in three different pHs of treatment. Results can be observed in Table 3 (treatment stages of 5, 6, 7, 8, 9 and 10). According to the results of this study (Table 3 , stages 1 to 4 ), it should be concluded that Phenol removal is not significant without use of UV light. Besides, Phenol treatment by merely $\mathrm{pH}$ changes was not considered a successful process (Table 3, stage 1) and high efficiencies of Phenol removal were obtained only by combination of UV light with $\mathrm{TiO}_{2}$ (Table 3; stages 5 to 10). The same results were also obtained in previous works (Kito, 1998) and it had been reported that photo catalytic oxidation of same organics as well as reduction of few metals is possible by coupling $\mathrm{TiO}_{2}$ with UV light. With the increasing of $\mathrm{pH}$, the solubility of metal decreases (Sawyer, et al., 2003).As shown in Table 3 and Figs. 2 to 4 , the treatment efficiencies of $\mathrm{Pb}$ and $\mathrm{Cd}$ removal could be both improved by $\mathrm{pH}$ increase. This means that $\mathrm{pH}$ treatment by itself had a significant effect on reduction of pollutants such that about $82 \%$ of Lead and $69.5 \%$ of Cd had been removed at appropriate pHs (Table 3, Stage 1). However, by applying photo catalysis process, the removal efficiencies had increased to as high as $98.8 \%$ for lead and $97.7 \%$ for Cadmium at the same appropriate $\mathrm{pHs}$ (Table 3; stage 10). This clearly indicates that photo catalysis can also be regarded as an applicable process for metals treatment. As it is shown in Table 3, the efficiency of Phenol degradation could be improved to a certain extant by addition of more $\mathrm{H}_{2} \mathrm{O}_{2}$ and $\mathrm{TiO}_{2}$. By increasing the $\mathrm{pH}$ of treatment, it should be possible to increase the removal rate of phenol and metals. By applying UV light and $\mathrm{TiO}_{2}$, Phenol could be degraded very well, and as shown in Table 3 (treatment stages of 5, 6 and 7), treatment was further improved by $\mathrm{pH}$ increase. 
M.R. Samarghandi, et al.

Table 3: Removal efficiency of phenol, $\mathrm{Pb}$ and $\mathrm{Cd}$ in $\mathrm{pH}=3.5,7$ and 11 in the various stages of experiments

\begin{tabular}{|c|c|c|c|c|c|c|c|c|c|c|}
\hline \multirow{3}{*}{ 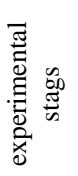 } & \multirow{3}{*}{$\begin{array}{l}\text { Experiment } \\
\text { condition }\end{array}$} & \multicolumn{9}{|c|}{ Removal efficiency } \\
\hline & & \multicolumn{3}{|c|}{$\mathrm{pH}=3.5$} & \multicolumn{3}{|c|}{$\mathrm{pH}=7$} & \multicolumn{3}{|c|}{$\mathrm{pH}=11$} \\
\hline & & Phenol & $\mathrm{Pb}$ & $\mathrm{Cd}$ & phenol & $\mathrm{Pb}$ & $\mathrm{Cd}$ & phenol & $\mathrm{Pb}$ & $\mathrm{Cd}$ \\
\hline 1 & $\begin{array}{l}\mathrm{H}_{2} \mathrm{O}_{2}=0(\mathrm{~mL} / \mathrm{L}) \\
\mathrm{TiO}_{2}=0(\mathrm{~g} / \mathrm{l}) \\
\mathrm{UV}^{*}=0\end{array}$ & 0.3 & 24.9 & 0.3 & 0.2 & 63 & 11.8 & 0.29 & 82.1 & 69.5 \\
\hline 2 & $\begin{array}{l}\mathrm{H}_{2} \mathrm{O}_{2}=1.1(\mathrm{~mL} / \mathrm{L}) \\
\mathrm{TiO}_{2}=0.1(\mathrm{~g} / \mathrm{l}) \\
\mathrm{UV}=0\end{array}$ & 7.44 & 34.9 & 0.8 & 6.4 & 80.3 & 23.1 & 6 & 84.5 & 72.1 \\
\hline 3 & $\begin{array}{l}\mathrm{H}_{2} \mathrm{O}_{2}=2(\mathrm{~mL} / \mathrm{L}) \\
\mathrm{TiO}_{2}=0.3(\mathrm{~g} / \mathrm{l}) \\
\mathrm{UV}=0\end{array}$ & 5.4 & 36.4 & 0.9 & 4.4 & 55.6 & 23.5 & 4 & 84.5 & 74.2 \\
\hline 4 & $\begin{array}{l}\mathrm{H}_{2} \mathrm{O}_{2}=3(\mathrm{~mL} / \mathrm{L}) \\
\left.\mathrm{TiO}_{2}=0.8 \mathrm{~g} / \mathrm{l}\right) \\
\mathrm{UV}=0\end{array}$ & 16.8 & 65 & 1.3 & 14 & 86.3 & 28.9 & 16.6 & 85.7 & 75.1 \\
\hline 5 & $\begin{array}{l}\mathrm{H}_{2} \mathrm{O}_{2}=0(\mathrm{~mL} / \mathrm{L}) \\
\mathrm{TiO}_{2}=0.05(\mathrm{~g} / \mathrm{l}) \\
\mathrm{UV}^{* *}=1\end{array}$ & 2.7 & 84.9 & 6.3 & 7.1 & 87.3 & 29.5 & 10 & 93.5 & 80.3 \\
\hline 6 & $\begin{array}{l}\mathrm{H}_{2} \mathrm{O}_{2}=0(\mathrm{~mL} / \mathrm{L}) \\
\mathrm{TiO}_{2}=0.1(\mathrm{~g} / \mathrm{l}) \\
\mathrm{UV}=1\end{array}$ & 3.71 & 91.3 & 10 & 4.2 & 92.8 & 38 & 12.7 & 94.7 & 90.1 \\
\hline 7 & $\begin{array}{l}\mathrm{H}_{2} \mathrm{O}_{2}=0(\mathrm{~mL} / \mathrm{L}) \\
\mathrm{TiO}_{2}=0.8(\mathrm{~g} / \mathrm{l}) \\
\mathrm{UV}=1\end{array}$ & 6.2 & 95.8 & 21 & 7.4 & 95.5 & 37.1 & 29.8 & 96.3 & 94.1 \\
\hline 8 & $\begin{array}{l}\mathrm{H}_{2} \mathrm{O}_{2}=1.1(\mathrm{~mL} / \mathrm{L}) \\
\mathrm{TiO}_{2}=0.1(\mathrm{~g} / \mathrm{l}) \\
\mathrm{UV}=1\end{array}$ & 14 & 93.3 & 18.5 & 22.1 & 96.6 & 34 & 38.5 & 96.6 & 95.1 \\
\hline 9 & $\begin{array}{l}\mathrm{H}_{2} \mathrm{O}_{2}=2(\mathrm{~mL} / \mathrm{L}) \\
\mathrm{TiO}_{2}=0.3(\mathrm{~g} / \mathrm{l}) \\
\mathrm{UV}=1\end{array}$ & 4.4 & 95 & 19 & 40 & 94.8 & 40.3 & 71 & 98.8 & 96.2 \\
\hline 10 & $\begin{array}{l}\mathrm{H}_{2} \mathrm{O}_{2}=3(\mathrm{~mL} / \mathrm{L}) \\
\mathrm{TiO}_{2}=0.8(\mathrm{~g} / \mathrm{L}) \\
\mathrm{UV}=1\end{array}$ & 51 & 96.6 & 26 & 44 & 96.7 & 46.9 & 76 & 98.8 & 97.7 \\
\hline
\end{tabular}

* without UV lamp *** with UV lamp

The same trend was also considered for metals treatment and both metals were removed much better when UV light was combined with $\mathrm{TiO}_{2} / \mathrm{H}_{2} \mathrm{O}_{2}$ (Table 3; stages 8, 9 and 10). In this study, maximum treatment efficiency of Phenol was $76 \%$ which was obtained at the stage 10 of the experiments (Table 3). Consumption of chemicals used for this treatment were $3 \mathrm{~mL} / \mathrm{L} \mathrm{H}_{2} \mathrm{O}_{2}$ and $0.8 \mathrm{mg} / \mathrm{L} \mathrm{TiO}_{2}$ and duration of UV irradiation was $180 \mathrm{~min}$. The same conditions were needed for maximum removal of $\mathrm{Cd}$ and $\mathrm{Pb}$ as well. Comparisons of 10 stage experiments at three pHs of 3.5, 7 and 11 can be seen in Figs. 2, 3 and 4, respectively. According to Fig. 2, in $\mathrm{pH}=3.5$ the efficiency of $\mathrm{Pb}$ removal during the stage 5 to 10 by $_{2} \mathrm{O}_{2} / \mathrm{TiO}_{2} / \mathrm{UV}$ process was very high(maximum $96.6 \%)$ but for phenol this efficiency is relatively high (max. 51\%) only at the stage of 10 . The conclusion

obtained by considering Fig. 3 indicates that the efficiencies of $\mathrm{Pb}$ removal were also high during all stages of these experiments (max. 96.7\% in the stage of 10) but for $\mathrm{Cd}$ and phenol, relatively high efficiences were obtained only in the stage 10 (for phenol $44 \%$ and for Cd 46.9 \%). In Fig. 4, relatively significant removal efficiency can be considered which is about $76 \%$ in respect to phenol at the stage of 10 and about $97.7 \%$ and $98.8 \%$ for $\mathrm{Cd}$ and $\mathrm{Pb}$, respectively, at the same stage.

Table 4: Maximum efficiency removal of phenol

\begin{tabular}{lccc}
\hline $\begin{array}{l}\text { Pollutants } \\
\mathrm{pH}\end{array}$ & Cadmium & Lead & Phenol \\
\hline 3.5 & 26 & 99.9 & 51 \\
7 & 39.9 & 99.8 & 44 \\
11 & 94.5 & 99.9 & 76 \\
\hline
\end{tabular}

$\mathrm{Pb}$ and $\mathrm{Cd}$ at $\mathrm{pH}=3.5,7,11$ 


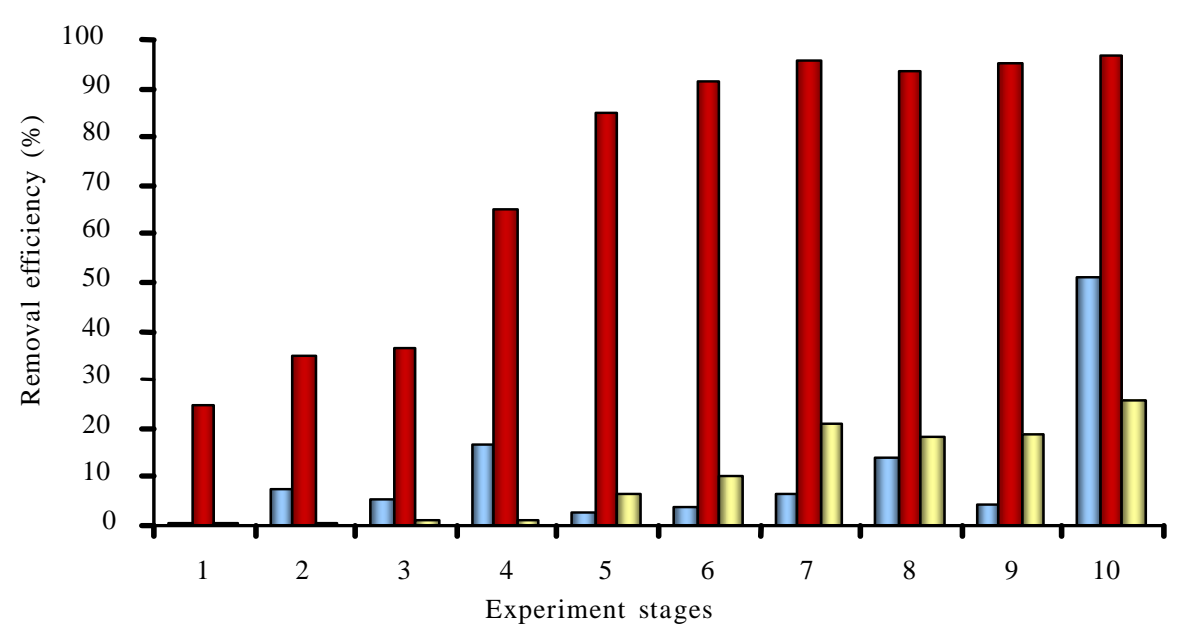

$\square$ phenol $\square \mathrm{Pb} \quad \square \mathrm{Cd}$

$\begin{array}{lllll}1: \mathrm{H}_{2} \mathrm{O}_{2}=0(\mathrm{~mL} / \mathrm{L}) & 2: \mathrm{H}_{2} \mathrm{O}_{2}=1.1(\mathrm{~mL} / \mathrm{L}) & 3: \mathrm{H}_{2} \mathrm{O}_{2}=2(\mathrm{~mL} / \mathrm{L}) & 4: \mathrm{H}_{2} \mathrm{O}_{2}=3(\mathrm{~mL} / \mathrm{L}) & 5: \mathrm{H}_{2} \mathrm{O}_{2}=0(\mathrm{~mL} / \mathrm{L}) \\ \mathrm{TiO}_{2}=0(\mathrm{~g} / \mathrm{L}) & \mathrm{TiO}_{2}=0.1(\mathrm{~g} / \mathrm{l}) & \mathrm{TiO}_{2}=0.3(\mathrm{~g} / \mathrm{L}) & \mathrm{TiO}_{2}=0.8(\mathrm{~g} / \mathrm{L}) & \mathrm{TiO}_{2}=0.05(\mathrm{~g} / \mathrm{L}) \\ \mathrm{UV}^{*}=0 & \mathrm{UV}=0 & \mathrm{UV}=0 & \mathrm{UV}=0 & \mathrm{UV}^{* *}=1 \\ & & & \\ 6: \mathrm{H}_{2} \mathrm{O}_{2}=0(\mathrm{~mL} / \mathrm{L}) & 7: \mathrm{H}_{2} \mathrm{O}_{2}=0(\mathrm{~mL} / \mathrm{L}) & 8: \mathrm{H}_{2} \mathrm{O}_{2}=1.1(\mathrm{~mL} / \mathrm{L}) & 9: \mathrm{H}_{2} \mathrm{O}_{2}=2(\mathrm{~mL} / \mathrm{L}) & 10: \mathrm{H}_{2} \mathrm{O}_{2}=3(\mathrm{~mL} / \mathrm{L}) \\ \mathrm{TiO}_{2}=0.1(\mathrm{~g} / \mathrm{L}) & \mathrm{TiO}_{2}=0.8(\mathrm{~g} / \mathrm{l}) & \mathrm{TiO}_{2}=0.1(\mathrm{~g} / \mathrm{L}) & \mathrm{TiO}_{2}=0.3(\mathrm{~g} / \mathrm{L}) & \mathrm{TiO}_{2}=0.8(\mathrm{~g} / \mathrm{L}) \\ \mathrm{UV}=1 & \mathrm{UV}=1 & \mathrm{UV}=1 & \mathrm{UV}=1 & \mathrm{UV}=1\end{array}$

Fig. 2: Removal efficiency comparison of phenol, $\mathrm{Pb}$ and $\mathrm{Cd}$ in various stages of experiments $(\mathrm{pH}=3.5)$

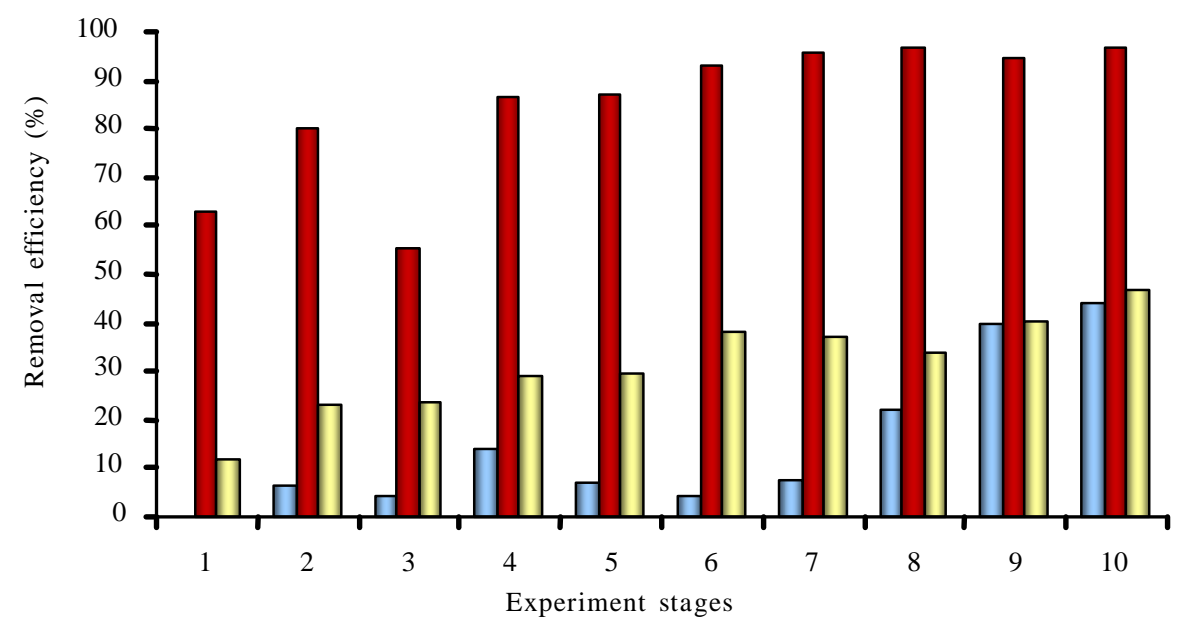

$\square$ phenol $\quad \square \mathrm{Pb} \quad \square \mathrm{Cd}$

$\begin{array}{lllll}1: \mathrm{H}_{2} \mathrm{O}_{2}=0(\mathrm{~mL} / \mathrm{L}) & 2: \mathrm{H}_{2} \mathrm{O}_{2}=1.1(\mathrm{~mL} / \mathrm{L}) & 3: \mathrm{H}_{2} \mathrm{O}_{2}=2(\mathrm{~mL} / \mathrm{L}) & 4: \mathrm{H}_{2} \mathrm{O}_{2}=3(\mathrm{~mL} / \mathrm{L}) & 5: \mathrm{H}_{2} \mathrm{O}_{2}=0(\mathrm{~mL} / \mathrm{L}) \\ \mathrm{TiO}_{2}=0(\mathrm{~g} / \mathrm{l}) & \mathrm{TiO}_{2}=0.1(\mathrm{~mL} / \mathrm{L}) & \mathrm{TiO}_{2}=0.3(\mathrm{~mL} / \mathrm{L}) & \mathrm{TiO}_{2}=0.8(\mathrm{~mL} / \mathrm{L}) & \mathrm{TiO}_{2}=0.05(\mathrm{~mL} / \mathrm{L}) \\ \mathrm{UV}^{*}=0 & \mathrm{UV}=0 & \mathrm{UV}=0 & \mathrm{UV}=0 & \mathrm{UV}^{* *}=1 \\ 6: \mathrm{H}_{2} \mathrm{O}_{2}=0(\mathrm{~mL} / \mathrm{L}) & 7: \mathrm{H}_{2} \mathrm{O}_{2}=0(\mathrm{~mL} / \mathrm{L}) & 8: \mathrm{H}_{2} \mathrm{O}_{2}=1.1(\mathrm{~mL} / \mathrm{L}) & 9: \mathrm{H}_{2} \mathrm{O}_{2}=2(\mathrm{~mL} / \mathrm{L}) & 10: \mathrm{H}_{2} \mathrm{O}_{2}=3(\mathrm{~mL} / \mathrm{L}) \\ \mathrm{TiO}_{2}=0.1(\mathrm{~g} / \mathrm{L}) & \mathrm{TiO}_{2}=0.8(\mathrm{~mL} / \mathrm{L}) & \mathrm{TiO}_{2}=0.1(\mathrm{~mL} / \mathrm{L}) & \mathrm{TiO}_{2}=0.3(\mathrm{~mL} / \mathrm{L}) & \mathrm{TiO}=0.8(\mathrm{~mL} / \mathrm{L}) \\ \mathrm{UV}=1 & \mathrm{UV}=1 & \mathrm{UV}=1 & \mathrm{UV}=1 & \mathrm{UV}=1\end{array}$

Fig. 3: Removal efficiency comparison of phenol, $\mathrm{Pb}$ and $\mathrm{Cd}$ in various stages of experiments $(\mathrm{pH}=7)$ 


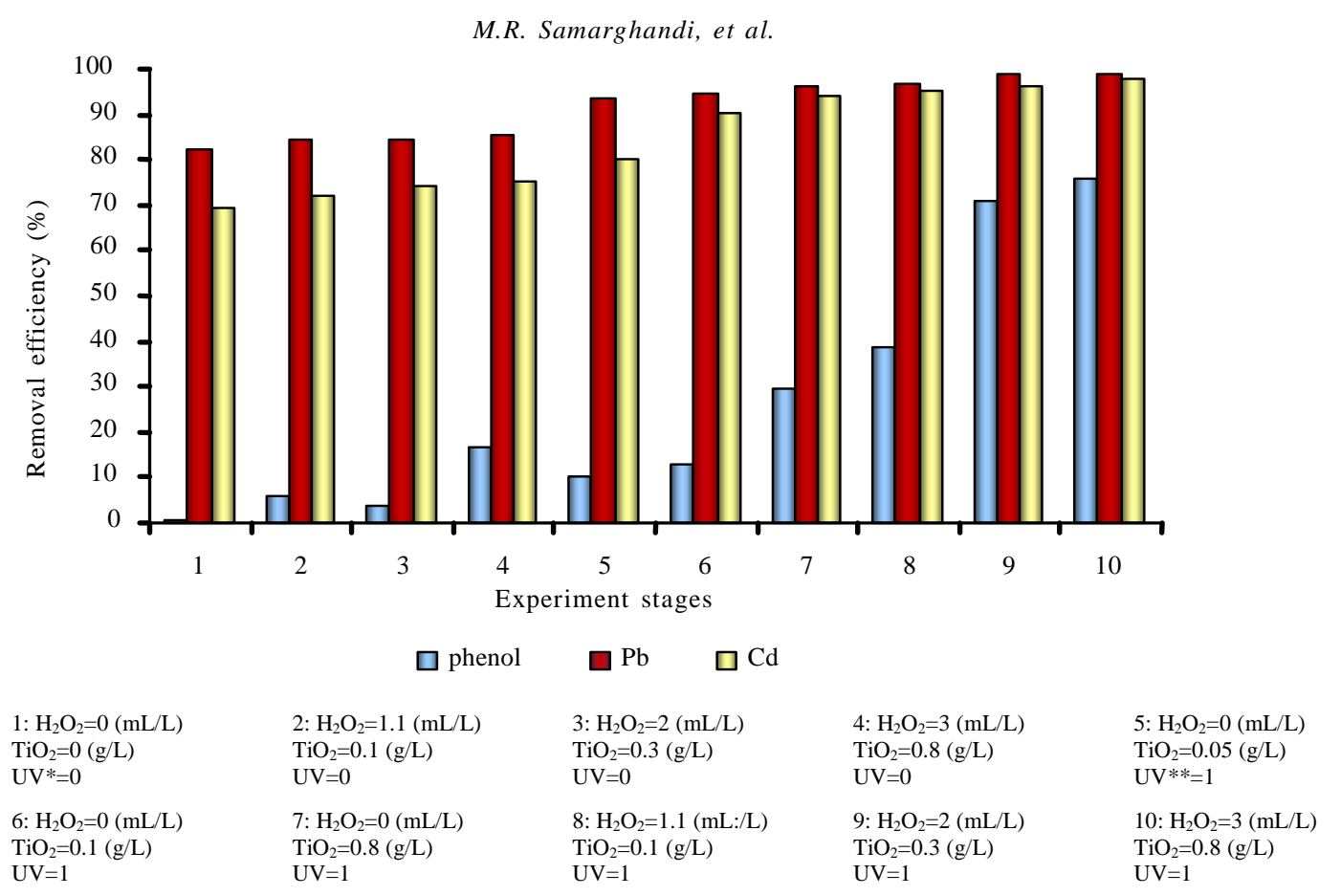

Fig. 4: Removal efficiency comparison of phenol, $\mathrm{Pb}$ and $\mathrm{Cd}$ in various stages of experiments $(\mathrm{pH}=11)$

\section{DISSCUSION AND CONCLUSION}

It could be concluded that any of the three pHs of 3.5, 7 and 11 can be used for Lead removal. Since, the main purpose of this study was to find a suitable treatment condition by which simultaneous removal of Phenol and two heavy metal could be accomplished, the $\mathrm{pH}$ of 11 should be preferred, because, at $\mathrm{pH}=11$ the efficiencies of treatment by $\mathrm{UV} / \mathrm{TiO}_{2} / \mathrm{H}_{2} \mathrm{O}_{2}$ had become maximized. However, relatively good condition of Phenol had been occurred at other pHs and so it is also feasible to have acceptable treatment results if less efficiencies sufficed (for example, in conditions where initial concentrations of Phenol and Cd are low). Finally, Table 4, which represents the maximum efficiencies obtainable at each $\mathrm{pH}$, helps us to meet the treatment standards so that the industrial wastewater can be treated.

\section{REFERENCES}

Akbal, F., Nur Onar, A., (2003). Photo catalytic degradation of phenol. Environ. Monit. Assess., 83 (3), 295-302.

Bekkouche, S., Bouhelassa, M., Hadj, Salah, N., Meghlaoui, F.Z., (2004). Study of adsorption of phenol on titanium oxide $\left(\mathrm{TiO}_{2}\right)$. Desalination, 166, 355-362.

Chen, D., Ray, Ajay, K., (2001). Removal of toxic metal ions from wastewater by semiconductor photocatalysis, Department of Chemical and Environmental Engineering, National University of Singapore,10 Kent Ridge Crescent, Singapore.
Clesceri, Lenore, S., Greenberg, Arnold, E. , Eaton and Andrew, D.,(2000). Standard methods for the examination of water and wastewater, $20^{\text {th. }}$ Ed., American Public Health

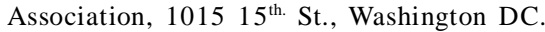

Daneshvar, N., Rabbani, M., Modirshahla, and N., Behnajady, M.A., (2004). Kinetic modeling of photo catalytic degradation of Acid Red 27 in $\mathrm{UV} / \mathrm{TiO}_{2}$ process, J. Phtotochem. Photobio., A-chemistry, 168, 39-45.

Daneshvar, N., Rabbani, M., Modirshahla, N., Behnajady, M.A., (2004). Critial effect of hydrogen peroxide concentration in photochemical oxidative degradation of C.I.Acid Red 27 (AR 27), J. Photochem. Photobio. A-chemistry, 56, 895900.

Desrosiers, K., Ingraham,W., Van Mate, A., (2006). $\mathrm{TiO}_{2}$ photocatalysis for organics, Available at: http:// Ceenve.Calpoly. Edu/cota/enve 436/Projectes/ $/ \mathrm{TiO}_{2}$ b/TiO ${ }_{2}^{-}$ Organics. html

Kito, M., Nguyen, H., Tran, J., (1998). Hydrogen peroxide and UV Treatment, Available at: http://www.Calpoly.edu/ $\sim$ Ceenve/enve/jsczechowski/enve436/projects/Hydro-perox/ Konstantinu, L., Sakkas, K., Vasilios, A., Albanis, Triantafylles A., (2002). Photocatalytic degradation of propachlor in aqueous $\mathrm{TiO}_{2}$ Suspensions, Wat. Res., 36, 2733-2742

Poudyal, K., Clark, D., Brag, A., (2006). Titanium dioxide photocatalysis of metals, Available at: http:// ceenve.calpoly.edu/cota/enve436/projects/Tio2 a/TiO2photocat.html.

Prairie, M., Evans, R., Lindsey, R., Martinez, S.L., (1998). Destruction of crganics and removal of heavy metals in water via $\mathrm{TiO}_{2}$ photo catalysis, Energy Conversion and Process Science Department, Sandia National Laboratories, Albuquerque, New Mexico 87185, USA. 
Sawyer, C.N., McCarty, P.L, Parkin, G.F., (2003). Chemistry for Environmental Engineering and Science, $5^{\text {th. }}$ Ed., McGraw -Hill Publisher.

Vidol, A., Diaz, A.I. „Hpiki, E.A., Romero, M., Muguruza, I., Senhaji, F., Gonzalez, J., (1999). Solar photo catalysis for detoxification and disinfection of contaminated water: pilot plant studies. Catalysis Today, 54 (2-3), 283-290.
Vohra, M., Shariq, Tanaka, K., (2002).Photo catalytic degradation of nitro toluene in aqueous $\mathrm{TiO}_{2}$ suspension, Wat. Res., 36 (1), 59-64.

\section{AUTHOR (S) BIOSKETCHES}

Samarghandi, M.R., M.Sc., Ph.D. Student, Department of Environmental Health Engineering, School of Public Health and Institute of Health Researches, Tehran University of Medical Sciences, Tehran, P. O. Box 14155-6446, Iran. Email: samar3468@yahoo.com

Nouri, J., Associate professor, Department of Environmental Health Engineering, School of Public Health and Institute of Health Researches, Tehran University of Medical Sciences, Tehran, P. O. Box 14155-6446, Iran. Email: jnouri@tums.ac.ir

Mesdaghinia, A.R., Professor and Chairman, Department of Environmental Health Engineering, Dean of School of Public Health and Institute of Health Researches, Tehran University of Medical Sciences, Tehran, P. O. Box 14155-6446, Iran. Email: mesdaghinia@sina.tums.ac.ir

Mahvi, A.H., Associate professor in Department of Environmental Health Engineering, School of Public Health and Institute of Health Researches, Tehran University of Medical Sciences, Tehran, P. O. Box 14155-6446, Iran. Email: ahmahvi@yahoo.com

Nasseri, S., Professor, Department, Environmental Health Engineering, School of Public Health and Institute of Health Researches, Tehran University of Medical Sciences, Tehran, P. O. Box 14155-6446, Iran. Email: simnasseri@hotmail.com

Vaezi, F., Associate professor, Department of Environmental Health Engineering, School of Public Health and Institute of Health Researches, Tehran University of Medical Sciences, Tehran, P. O. Box 14155-6446, Iran. Email: for_vaezi@yahoo.com

\section{This article should be referenced as follows:}

Samarghandi, M.R., Nouri, J., Mesdaghinia, A.R., Mahvi, A.H., Nasseri, S., Vaezi, F., (2007). Efficiency removal of phenol, lead and cadmium by means of $U V / T i O_{2} / H_{2} \mathrm{O}_{2}$ processes. Int. J. Environ. Sci. Tech., 4 (1), 19-25. 